\title{
健康城市规划路径与要素辨析
}

\section{Exploration of Approaches and Factors of Healthy City Planning}

王兰 廖舒文 赵晓菁

Wang Lan, Liao Shuwen, Zhao Xiaojing

摘要: 健康城市的规划与设计日益获得关注, 一方面城市环境问题突 显, 特别是发展中国家因工业化造成的空气污染等; 另一方面城市居 民对身心健康的诉求, 需要物质空间支撑生活品质的提升。本文通过 理论和实证的文献研究, 明确健康城市规划中重要的空间要素, 分析 不同路径下各类空间要素与健康的相关性。基于减少污染及其对人体 的影响和促进锻炼两种路径, 从土地使用、空间形态、道路交通、绿 地及开放空间四方面阐述各规划要素与公共健康的关联, 以期为健康 城市规划和相关研究提供依据。

Abstract: Planning and design for healthy city has drawn increasingly extensive attention. On the one hand, urban environmental issues have become prominent, especially air pollution caused by industrialization in developing countries; on the other hand, urban residents' demand for physical and mental health calls for physical space to promote the quality of life. Based on theoretical and empirical researches, this paper explores significant spatial factors in healthy city planning and their correlation with public health in different approaches. In order to reduce pollution and its impact on human as well as encourage exercise, the correlations are elaborated from four perspectives: land use, spatial form, road and transport, green space and open space, with a view to provide basis for healthy city planning and its related studies.

关键词: 健康城市; 研究路径; 规划要素

Keywords: Healthy City; Research Approach; Planning Factors

国家自然科学基金项目 (51578384), 上海市科学技术委员会科研计划 项目 (14411951200) 共同资助

作者: 王兰 (通信作者), 同济大学建筑与城市规划学院城市规划系副教 授，博士生导师。wanglan@tongji.edu.cn 廖舒文, 同济大学建筑与城市规划学院城市规划系, 硕士研究生 赵晓菁 (通信作者), 上海交通大学医学院附属仁济医院胸外科主 任医师; 美国纪念斯隆一凯特琳癌症中心和梅奥临床中心访问学者。 zhaoxiaojing@renji.com

\section{引言}

现代城市规划一直致力于提升城乡居民的健康生活水 平; 其缘起与公共健康关系密切, 在 1900 年前后城市规划 通过规范建筑的日照、通风等方面, 干预和改善城市公共卫 生。随着基本健康问题在物质环境方面的保障, 公共健康一 度远离了城市规划的关注重点。然而目前居民对生活品质和 身心健康要求的提升, 环境污染导致的呼吸系统疾病, 营养 过剩导致的肥胖、心脏病等问题, 引发了新一轮城乡规划学 科与公共健康的跨学科研究。我国健康城市的实证基础研究 方兴未艾; 从研究分析落实到空间的规划设计仍需要从理论 到实践的传递和互动。本文通过相关理论和实证的文献研究, 明确健康城市规划中重要的空间要素, 分析不同路径下各类 空间要素与健康的相关性。

\section{1 健康城市规划路径}

世界卫生组织（WHO）在 1984 年多伦多召开的 “2000 年健康多伦多” 大会上,第一次提出了 “健康城市” (Healthy City）的概念 ${ }^{[1]}$; 提出在公众、健康和自愿参与的部门、机 构、组织之间广泛合作, 重点解决城市卫生及与健康相关的 问题。WHO 对于健康城市的具体定义于 1994 年提出, 即 “一 个健康城市应该是由健康的人群、健康的环境和健康的社会 有机结合的一个整体, 应该能不断地改善环境、扩大社区资 源, 使城市居民能互相支持, 以发挥最大的潜能” [2]。随后, 欧洲部分地区和城市启动了 “健康城市项目” (Healthy City Project)。目前欧洲的健康城市建设重点工作包括健康城市 规划、创造支持性环境、健康影响评估、提倡积极的生活方 式等 ${ }^{[3]}$ 。东京市政府也在 1990 年启动了健康城市计划并成 立了东京市民委员会, 以场所为基础（包括家庭、社区、学 校和单位), 开展了分别针对儿童、成年人和老年人的健康 
促进活动, 同时致力于改善卫生服务, 创造支持性环境, 建 立社区健康生活方式 ${ }^{[4]}$ 。

城市规划对公共健康的影响主要体现在各规划要素对城 市环境、人们的行为模式、心理状态等方面的影响。笔者将 本学科对公共健康的促进作用总结为两个路径：(1) 消除和 减少具有潜在致病风险的建成环境要素; (2) 推动健康低碳 的生活、工作、交通和娱乐方式。因此, 本文将从两种路径 进行文献分析, 分别是减少污染及其对人体的影响和促进锻 炼。其中减少污染是减少污染物的排放, 例如降低空气中颗 粒物浓度、减少颗粒物的有毒成分; 减少污染对人体的影响 指采取一定的防护措施和规划方法, 避免污染物扩散至人群 聚集的地方, 减少人体对颗粒物的吸人等。促进锻炼是致力 于提高人们进行体能活动的意向、时间和频率。通过这两种 路径, 本文将辨析四类规划空间要素的健康影响, 包括土地 使用、空间形态、道路交通、绿地和开放空间（图 1)。

\section{2 规划要素对公共健康的影响}

\section{1 土地使用}

土地使用对公共健康的影响要素可以划分为土地使用类 型、强度和混合程度。从减少污染及其人体影响的角度, 可 通过限制具有污染风险的用地 (例如工业用地、交通用地) 在人口集聚地区的规划设置, 降低人群的污染暴露度, 增设 绿地改善大气质量 ${ }^{[5]}$ 。土地开发的适度高强度和混合使用, 将有利于将交通需求内部化, 缩短出行距离, 减少碳排放和 空气污染。从促进锻炼的角度, 功能多元的混合开发和宜人 的环境设计, 将有助于引导居民选择慢行交通的出行方式, 提高体能活动的频率。

土地使用类型的规模、分布和与周边用地的关系决定了 其对公共健康的影响。在整体层面上, 城镇建设用地的增加 不利于大气污染物的扩散 ${ }^{[6]}$ 。在具体土地使用类型中, 工业 用地和交通用地存在污染隐患, 部分商业设施用地 (如打印 店、干洗店、照片洗印店等)、市政设施用地（如垃圾填埋 场或焚化厂、垃圾转运站、污水处理厂) 和物流仓储用地（如 危险品仓库、物流配送中心）具有污染风险 ${ }^{[7-9]}$ 。在规划和
具体项目选址中, 通过在污染源和附近敏感土地使用地区之 间提供一个适当的距离或防护措施 ${ }^{[9]}$, 可以避免污染物影响 至敏感人群的活动范围。在增强锻炼方面, 规划规定土地使 用类型应在步行和骑行范围内增加不同人群的活动目的地, 例如日常生活所需的菜市场、便利店、大中型超市、电信网 点、诊所药店和五金维修等设施, 均有利于降低家庭非通勤 类机动车出行能耗 ${ }^{[10]}$; 幼儿园、中小学、书报亭等功能性目 的地将鼓励学生步行或骑行上学, 促进不同年龄段人群的日 常体育活动 ${ }^{[1]}$ 。

土地开发强度表征了单位土地的使用程度, 通常以容积 率、建筑层数等指标来衡量。高强度土地开发配合适度的土 地混合, 可使居民在城市空间中的活动相对集中在一个较小 的空间范围内, 通过步行和骑行等慢性交通出行方式, 减少 私人汽车的出行机率和距离, 从而降低居民出行的碳排放总 量 ${ }^{[12]}$ 。紧凑的土地开发模式还可以增强街道生活活力, 促进 邻里经济发展和居民步行 ${ }^{[13]}$ 。

土地混合使用强调在特定空间区域内设置多类型的土地 使用, 其混合程度可通过土地混合使用率 ${ }^{[14]}$ 、赫芬达尔一赫 希曼指数 (HHI: Herfindahl-Hirschman Index) ${ }^{[15]}$ 来衡量。土 地混合使用体现在通过鼓励步行和骑行来减少机动车污染。 刘志伟将南京主城区的 198 个交通小区划分为 26 个中区作 为研究对象, 选取 6 个中区作为待优化区域, 考虑四种用地 类型：居住用地、商业用地、工业用地和娱乐用地, 通过交 通生成预测模型, 表明通过合理优化土地利用布局, 增强不 同土地利用之间的协调性, 提高区域的可达性, 可以使交通 需求内部化, 缩短出行距离 ${ }^{[16]}$ 。冯红霞等通过模型和大量数 据测定出: 适宜步行出行的空间距离为 $2 \mathrm{~km}$ 以内, 适宜自 行车出行的空间距离为 $4.2 \mathrm{~km}$ 以内, 适宜公共交通出行的 距离为 $9.6 \mathrm{~km}$ 以内 ${ }^{[17]}$ 。因此, 如果在 $2 \mathrm{~km}$ 范围内实现居住 与生活服务的混合配置, 在 $5 \mathrm{~km}$ 范围内实现居住与就业岗 位的混合配置, 可将大多数的通勤交通出行控制在短距离出 行中。单体建筑垂直向度上各功能的组合也有助于将对外出 行转为内部出行。相关研究表明, 在集聚有零售商业、商务 办公等多功能楼面的邻里单元中 (距邻里中心 $400 \mathrm{~m}$ 的步行

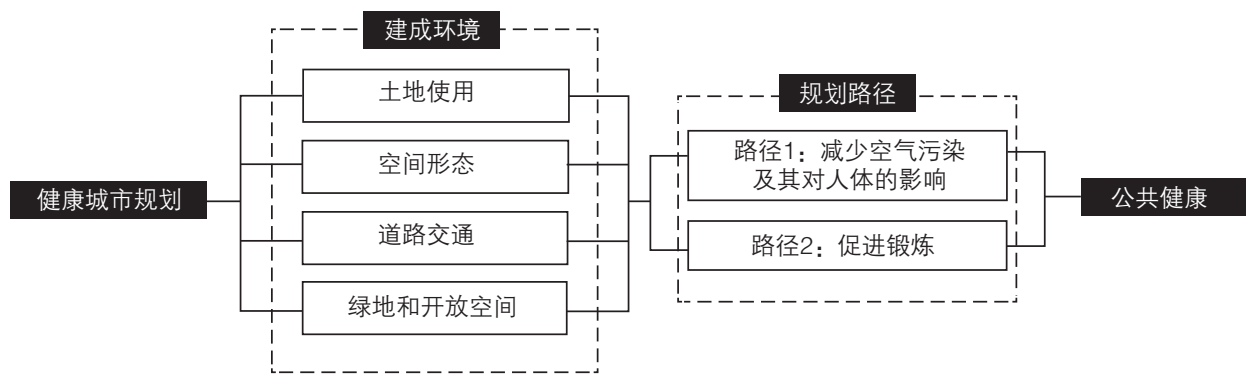


活动范围内), 当垂直混合度为 1 , 其产生的交通周转量比 单一功能楼面的建筑少 11 车. 英里 ${ }^{[18]}$ 。此外, 存在污染风 险的用地混合叠加可能加重潜在的污染风险 ${ }^{[9]}$, 应该避免存 在污染风险的混合用地规划。

同时, 定量研究发现土地混合使用能够鼓励步行和活动, 特别是 65 岁以上的老年人群 ${ }^{[19]}$ 。张莹抽取了上海市杨浦区、 卢湾区和闵行区的 13 个街道/镇的 80 个居委会, 900 位 46 80 岁的中老年人受试者, 以居民的体质健康（体能活动、 健康状况）以及住区人居环境为研究对象构建模型, 发现对 步行数的影响要素中, 显著性由大到小分别是街道连通性、 与公园的距离、人均道路面积、人口净密度、与广场的距离、 土地混合使用率和人均绿地面积。其中混合使用率、街道连 通性、人均绿地面积和步行数呈正相关, 与公园和广场的距 离、人均道路面积、人口净密度和步行数呈负相关 ${ }^{[20]}$ 。

\section{2 空间形态}

在空间形态对公共健康的影响研究方面, 目前以针对城 区肌理形态和街道空间几何形态的研究为主。从控制污染的 角度, 现有研究证实城市风环境及空气质量与城区肌理形态、 街道空间的几何形态变化直接相关 ${ }^{[21]}$ 。城区肌理形态和街道 空间的几何形态影响城市的局部风环境, 决定污染物的扩散。 从促进锻炼的角度, 适宜尺度的街区和街道空间能够促进人 们自发地选择慢行交通出行方式, 增加体能活动。

城区肌理形态可以通过两个层次的指标来表述, 第一个 层次是地块控制指标, 包括容积率、建筑密度和建筑高度; 第二个层次是地块内建筑群整合度和离散度等 ${ }^{[21]}$ 。久保田 哲等人通过对 22 个住宅街区阵列模型进行风环境模拟, 证 实街区内的建筑密度越高, 街区内平均风速越小 ${ }^{[22]}$, 而风 速过低对于大气污染物的扩散不利。与大尺度街坊相比较, 小尺度街坊在空间形式上的显著特点表现为具有高度连续 性和渗透性、适宜的街坊和街道尺度、适宜步行并具有活 力的公共空间 ${ }^{[23]}$ 。

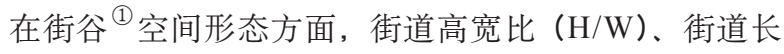
高比 $(\mathrm{L} / \mathrm{H})$ 、两侧建筑高度比 $\left(\mathrm{h}_{2} / \mathrm{h}_{1}\right)$ 是影响街谷气流、污 染物扩散和稀释的主要因素 ${ }^{[24]}$ 。邱巧玲等通过整合总结之前 国外的相关研究进行模型检验, 得出了针对控制街谷污染的 相关导则, 例如理想的街谷高宽比是 $H / W=1$, 实际工作中宜 控制在 $0.6 \sim 1.2$ 之间, 当街谷两侧建筑高度比 $h_{2} / h_{1}<1$ 或 $h_{2} / h_{1}$ 等于 2 左右时有利于街谷污染浓度的降低 ${ }^{[25]}$ 。同时, 王纪武 等以杭州市为案例, 对街谷形态和污染物进行实证分析, 发 现街谷内部的风速较小, 加之机动车不断排放废气, 使与街
谷平行的清洁气流被迅速污染, 成为污染物汇集的空间 ${ }^{[24]}$ 。 因此城市的通风系统应由 “给风系统” 和 “排风系统” 两个 子系统构成。给风系统以开敞的绿化空间为主, 适宜布置在 城市常年主导风向的上风向; 排风系统则应以城市交通干道 为主。住宅建筑适宜布置在街谷的下风向, 而公共建筑适宜 布置在街谷的上风向。这样的实证研究为健康导向的城市空 间形态设计提供了依据。

\section{3 道路交通}

道路交通对公共健康的影响因素可分为机动交通和慢行 交通。从控制污染的角度, 机动交通的排放是空气污染的主 要来源之一 ${ }^{[26]}$, 通过减少机动车出行、鼓励慢行交通, 可降 低污染的产生。从促进锻炼的角度, 推广步行和骑行的出行 方式有益于减少肥胖、高血压、糖尿病和心血管疾病。但机 动交通和慢行交通线路的重叠将增加人体对污染物的暴露剂 量 (或污染暴露度), 即人体所吸人的颗粒物剂量, 需要通 过一定的设计减轻此类污染物对慢行出行者的影响。

机动交通增加空气污染物及人体对污染物的暴露剂量。 研究指出, 欧洲 $70 \%$ 的空气污染物和 $40 \%$ 的温室气体排放 都来自于机动交通 ${ }^{[27]}$ 。侯芳和陈刚才等在北京和重庆的研 究显示, 道路密度、车流量与空气颗粒物浓度呈正相关 ${ }^{[28,29]}$ 。 关于澳大利亚户外空气质量的研究表明, 污染物浓度随着与 主干道的距离增加而下降, 居民呼吸健康问题也随之减少 ${ }^{[30]}$ 。 基于旧金山湾区的研究也发现，儿童哮喘和支气管炎的症状 与高流量道路之间具有相关性。对加拿大安大略省 5228 名 居民的调查发现, 居住在距离城市主干道 $50 \mathrm{~m}$ 以内或高速 公路 $100 \mathrm{~m}$ 以内且无绿化遮挡的居民, 呼吸系统患病死亡率 与该区域的空气环境指数息息相关 ${ }^{[31]}$ 。针对美国加州南部的 研究显示, 交通相关污染物在距离高速路约 $90 \mathrm{~m}$ 处有显著

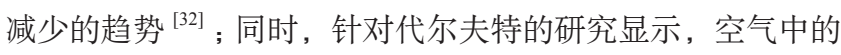
交通污染物浓度在距离道路约 $150 \mathrm{~m}$ 处下降程度明显 ${ }^{[33]}$ 。由 此加州政府通过了一项空气质量法令, 禁止在距离高速交通 廊道或其他大交通量道路 $150 \mathrm{~m}$ 内建设新的学校。此外, 对 小汽车的依赖降低了健身活动的需求, 提高了肥胖症等慢性 病的发病风险, 增加了行车途中与停车场人体吸人污染物的 剂量 ${ }^{[34]}$ 。例如, 以哥本哈根为案例的研究证明, 小汽车使用 者所接触到的污染物浓度是骑行者的四倍 ${ }^{[35]}$ 。

在慢行交通方面, 已有研究证实了步行与骑行对健康的 积极作用。步行和骑行者在高血压、糖尿病及心血管病方面 的发病率均较低 ${ }^{[36]}$ 。在对 67000 名上海女性进行了平均长 达 5.7 年的跟踪调查中发现, 以步行与骑行为主要交通方式 
的研究对象, 也呈现疾病发病率低的情况 ${ }^{[37]}$ 。同时研究发现, 公共交通的使用和体能活动存在关系，因为使用公共交通通 常会步行前往公共汽车或地铁站点 ${ }^{[38]}$, 从而增加了活动量。

需要在城市规划和设计中考虑的是, 步行与骑行路径若 与机动交通重叠, 则步行者与骑行者易暴露于机动车排放出的 尾气之中。欧洲研究发现, 骑行路径在交通量小的道路或在自 行车专用道上, 人体的污染暴露度低 ; 但如果在机动车较多的 街道上, 由于呼吸速率随骑行运动相应加快, 骑行者的污染物 暴露剂量是同一路段上小汽车乘客的 4 7 倍 ${ }^{[39]}$ 。因此设计慢 行系统时应尽量避开机动交通繁忙的路段, 或通过分隔绿带降 低出行者的污染物暴露剂量。针对旧金山的研究发现, 增加自 行车专用道并加宽街道后, 骑行人数可增长 $2 \sim 3$ 倍 ${ }^{[40]}$ 。

此外, 国外健康城市建设的重点在于如何为人们提供 有活力的空间, 以此促进锻炼, 鼓励慢行和公共交通。1990 年初, 挪威在由其环境部发起的国家级项目中明确健康城市 规划的主要目标为: 减少机动交通, 鼓励骑行、步行和公共 交通。其具体措施包括 : 建设骑行道路网络, 绘制区域骑行 地图, 为骑行者规划休闲路径, 规划建设免费自行车系统 ${ }^{[41]}$ 。 在美国, 旧金山东湾绿道的健康影响评估 ${ }^{[42]}$ 提出最大限度 减少机动车辆使用的策略, 包括多个项目合作实现安全的慢 行交通路线, 强化街区内部的自行车道和人行道的连接性等, 还提出了在设计细节中增加居民在绿道上开展体育活动的方 法: 保证活动的安全感和舒适性, 分离自行车和步行路径, 配合绿道布置饮水机、自行车架等停车设施, 配置遮蔽绿荫 和绿道里程标记等。2010 年纽约市编制的《促进锻炼和健 康的城市活力空间设计导则》 ${ }^{[40]}$ 中, 为促进公共和慢行交 通的使用, 提出了加宽人行道、增加照明设施、机动车/自 行车停车和公交站点的结合、提高道路和开放空间的连接等 常规设计要点, 同时还提出设置健康地图（在地图上标注到 最近的或下一个交通站点的距离、时间、路线和热量消耗), 开展创新设计, 为不同季节和天气条件提供促进活动的环境。 洛杉矶的《健康城市建设》 ${ }^{[43]}$ 中则提出了针对步行、骑行、 公交站点和开放公共空间的四类友好设计导则, 将其中的设 计要素分为人行道、步行设施、视线吸引点、自行车网络、 骑行环境、候车站点等, 并提出相应的指导原则。

\section{4 绿地和开放空间}

绿地和开放空间对公共健康的影响主要体现在规模、布 局和植物配置三个方面。从控制污染的角度, 绿地的规模效 应和合理布局有助于形成城市的通风廊道, 合理的植物配置
能够最大化地净化空气和吸收粉尘 ${ }^{[4,45]}$ 。从促进锻炼的角度 来看, 绿地和开放空间的合理布局能够提高可达性, 鼓励人 们使用这些空间进行锻炼活动。

绿地的规模大小对吸收空气中污染物的效果存在影响。 有研究指出, 城市街谷近地处 (尤其是行人的呼吸高度附 近）是机动车尾气污染最为严重的区域, 需要借助绿化隔离 带的隔离与净化作用, 改善城市街谷近地处的空气质量 ${ }^{[24]}$ 。 根据研究, $50 \mathrm{~cm}$ 高的植物边界墙可显著降低污染物向人行 道的扩散, 减少比例达 $46 \% \sim 65 \%{ }^{[46]}$ 。林带宽度超过 $30 \mathrm{~m}$, PM2.5 的值有较大下降 ${ }^{[47]}$ 。公园绿地消减 PM2.5 能力与公 园规模呈正相关, 公园规模越大, PM2.5 去除水平越高, 因 此应尽量配置大中规模的绿地。

在绿地和开放空间的布局方面, 系统网络化的布局有利 于大幅减少空气中的可吸人颗粒物, 改善城市气候 ${ }^{[4]}$ 。冯涃 慧等通过 GRAPES 大气模拟模式 ${ }^{1}$, 计算模拟广州市绿色空 间对大气环境的影响。证明通过一定规模面积的绿地系统布 局, 能增强城市气流输送, 激发城市中尺度次级环流, 进而 改善周围环境温度 ${ }^{[48]}$ 。刘姝宇等通过德国居住区的案例分析, 发现将小型绿地整合为几个均匀分布的大中型绿地, 有利于 抑制城市热岛的扩散，而绿地和开放空间的布局同时涉及可 达性 ${ }^{[49]}$ 。通常绿地和开放空间的数量越多, 均衡度越高, 空 间分布越均匀, 则可达性越高 ${ }^{[50]}$ 。在基于洛杉矶的研究中 ${ }^{[51]}$, 居住在公园附近 2 英里 (约 $3 \mathrm{~km}$ ) 以内的运动者更易到公 园锻炼（占总居民人口中的 $34 \%$ ), 在家里锻炼的约占 $21 \%$, 在私人俱乐部锻炼的为 $6 \%$, 或在其他地点进行锻炼 $(39 \%)$ 。 $81 \%$ 的公园使用者都居住在公园 1 英里（约 $1.6 \mathrm{~km}$ ）范围内, 每周到公园的频率为四次及以上。

在绿地植物配置方面, 研究发现乔灌草复合搭配的绿 地对净化空气、吸收粉尘、为居民带来健康环境的效果最 佳 ${ }^{[52-54]}$; 并且以乔木为主的复层结构城市绿地保健效果较好, 即对人体健康具有促进作用, 主要包括净化空气、固碳释氧、 降噪、改善小气候及产生空气负离子等 ${ }^{[33]}$ 。城市高空绿化 是干预城市微气候的主要因素, 种植屋面可以改善空气质 量, 屋面植被可以过滤和绑定空气中的尘埃粒子, 自然过 滤空气中的毒素 ${ }^{[1]}$ 。

\section{3 健康城市规划要素}

健康城市规划涉及到土地使用、空间形态、道路交通、 绿地与开放空间四个要素的多个方面, 根据两个不同的规划 干预路径, 本文整理了不同规划要素的关键点及其涉及到的

(1) Global/Regional Assimilation and Prediction System, 简称 GRAPES, 是一种大气模拟模式, 为华南中尺度区域模式, 是我国发展并投入国家气 象预报的准入模式之一。 
文献 (表 1)。在减少污染及其人体影响方面, 目前研究多 关注与不同用地之间的距离关系, 主要为居住和公共服务设 施用地到工业、交通等具有污染风险用地之间的空间关系, 同时希望通过城市不同尺度的空间形态设计, 改善风场以减 轻空气污染。在促进锻炼方面, 强调空间的品质和活力, 涉 及慢行交通、绿地和开发空间的细节设计。其中论证相对充 分的规划要素包括 : 土地使用类型、街谷形态、机动交通、 慢行交通、绿地和开放空间的规模; 需要实证研究进一步深 人分析的规划要素包括: 土地使用强度、土地使用混合程度、 城区肌理形态、绿地和开放空间的布局和植物配置。

\section{4 结语}

健康城市的规划与设计日益获得关注, 一方面城市环境 问题突显, 特别是发展中国家因工业化造成的空气污染等; 另一方面城市居民对身心健康的诉求, 需要物质空间支撑

\section{表 1 健康城市规划要素}

\begin{tabular}{|c|c|c|c|c|}
\hline \multicolumn{2}{|c|}{ 规划要素 } & 规划路径 & 关键词 & 文献编号 \\
\hline \multirow{6}{*}{$\begin{array}{l}\text { 土 } \\
\text { 地 } \\
\text { 使 } \\
\text { 用 }\end{array}$} & \multirow{2}{*}{ 类型 } & $\begin{array}{l}\text { I 减少污染及其对 } \\
\text { 人体的影响 }\end{array}$ & $\begin{array}{l}\text { 整体建设用地规模; 具有污 } \\
\text { 染风险的用地类型 }\end{array}$ & $6-9$ \\
\hline & & II 促进锻炼 & $\begin{array}{l}\text { 步行和骑行范围内的活动目 } \\
\text { 的地 }\end{array}$ & 10,11 \\
\hline & \multirow[t]{2}{*}{ 强度 } & $\begin{array}{l}\text { I 减少污染及其对 } \\
\text { 人体的影响 }\end{array}$ & 出行距离 & 12 \\
\hline & & II 促进锻炼 & 街道活力 & 13 \\
\hline & \multirow{2}{*}{$\begin{array}{l}\text { 混合 } \\
\text { 程度 }\end{array}$} & $\begin{array}{l}\text { I 减少污染及其对 } \\
\text { 人体的影响 }\end{array}$ & $\begin{array}{l}\text { 土地使用协调性 ; 适宜的步 } \\
\text { 行和骑行距离 }\end{array}$ & $9,16-18$ \\
\hline & & II 促进锻炼 & $\begin{array}{l}\text { 混合使用率; 街道连通性 ; } \\
\text { 人均道路面积 ; 公园和广场 } \\
\text { 的距离 ; 人均绿地面积 }\end{array}$ & 19,20 \\
\hline \multirow{3}{*}{$\begin{array}{l}\text { 空 } \\
\text { 间 } \\
\text { 形 } \\
\text { 态 }\end{array}$} & \multirow{2}{*}{$\begin{array}{l}\text { 城区 } \\
\text { 肌理 } \\
\text { 形态 }\end{array}$} & $\begin{array}{l}\text { I 减少污染及其对 } \\
\text { 人体的影响 }\end{array}$ & 建筑密度 ; 街坊大小 & 22 \\
\hline & & II 促进锻炼 & 小尺度；连续性 ; 渗透性 & 23 \\
\hline & $\begin{array}{l}\text { 街谷 } \\
\text { 形态 }\end{array}$ & $\begin{array}{l}\text { 减少污染及其对 } \\
\text { 人体的影响 }\end{array}$ & $\begin{array}{l}\text { 街道高宽比; 街道长高比; } \\
\text { 两侧建筑高度比; 建筑与街 } \\
\text { 谷位置关系 }\end{array}$ & 24,25 \\
\hline \multirow{3}{*}{$\begin{array}{l}\text { 道 } \\
\text { 路 } \\
\text { 交 } \\
\text { 通 }\end{array}$} & $\begin{array}{l}\text { 机动 } \\
\text { 交通 }\end{array}$ & $\begin{array}{l}\text { I 减少污染及其对 } \\
\text { 人体的影响 }\end{array}$ & $\begin{array}{l}\text { 道路密度; 车流量 ; 居住用 } \\
\text { 地或公共设施用地与道路的 } \\
\text { 距离 }\end{array}$ & $26-35$ \\
\hline & \multirow{2}{*}{$\begin{array}{l}\text { 慢行 } \\
\text { 交通 }\end{array}$} & $\begin{array}{l}I \text { 减少污染及其对 } \\
\text { 人体的影响 }\end{array}$ & $\begin{array}{l}\text { 慢行系统与机动交通之间的 } \\
\text { 隔离 }\end{array}$ & 39 \\
\hline & & II 促进锻炼 & 慢行系统细节设计 & $36-38,40-43$ \\
\hline \multirow{3}{*}{$\begin{array}{l}\text { 绿 } \\
\text { 地 } \\
\text { 和 } \\
\text { 开 } \\
\text { 放 }\end{array}$} & 规模 & $\begin{array}{l}\text { I 减少污染及其对 } \\
\text { 人体的影响 }\end{array}$ & 特定高度、宽度和面积 & $24,46,47$ \\
\hline & \multirow[t]{2}{*}{ 布局 } & $\begin{array}{l}\mathrm{I} \text { 减少污染及其对 } \\
\text { 人体的影响 }\end{array}$ & 大中型 ; 网格化 & $44,48,49$ \\
\hline & & II 促进锻炼 & 可达性 & 50,51 \\
\hline $\begin{array}{l}\text { 空 } \\
\text { 间 }\end{array}$ & $\begin{array}{l}\text { 植物 } \\
\text { 配置 }\end{array}$ & $\begin{array}{l}I \text { 减少污染及其对 } \\
\text { 人体的影响 }\end{array}$ & 乔灌草复合搭配 ; 种植屋面 & \begin{tabular}{|l|}
$21,44,45$ \\
$52-54$ \\
\end{tabular} \\
\hline
\end{tabular}

资料来源 : 作者整理绘制
生活品质的提升。总体来看, 在我国城市语境下的健康城 市规划的研究和实践处于初级阶段, 针对特定空间要素的 理论和实证研究有待进一步加强。本文提出, 健康城市规 划的路径包含了减少污染及其对人体的影响的底线, 也包 含了促进锻炼的上线。不同的空间要素为健康城市规划提 供了控制引导对象。基于理论和实证研究的文献分析, 本 文对影响公共健康的规划要素进行分类讨论, 土地使用主 要在于其类型、强度和混合程度; 空间形态主要在于城市 肌理和街谷形态; 道路交通主要在于机动交通和慢行交通 的设计; 绿地和开放空间主要在于规模、布局和植物配置。 本文明确了各类要素在减少污染和促进健康两个路径的规 划原则, 其中特定要素明确了一定的指标, 指出了需要进 一步深人分析的规划要素类别, 为开展健康城市规划实践 和相关实证研究提供了基础。UP

感谢同济大学建筑与城市规划学院学生古佳玉、徐辰、周 薇銪、唐思远、林堉卉、庞健参与文献的翻译和整理工作。

\section{参考文献}

[1] 陈柳钦. 健康城市建设及其发展趋势 [J]. 中国市场, 2010(33): 50-63.

[2] 玄泽亮, 魏澄敏, 傅华. 健康城市的现代理念 [J]. 上海预防医学, 2002, 14(4): 197-199.

[3] 玄泽亮, 傅华.城市化与健康城市 [J]. 中国公共卫生, 2003, 19(2): 236238.

[4] 蒋莹, 常春. 国内外健康城市建设实践 [J]. 中华预防医学杂志, 2012, 46(8).

[5] Groenewegen P P, Vries S D. Is a Green Residential Environment Better for Health? If So, Why?[J]. Annals of the Association of American Geographers, 2012, 102(5): 996-1003.

[6] 迟妍妍, 张惠远, 饶胜, 等。珠江三角洲土地利用变化对特征大气污染 物扩散的影响 [J]. 生态环境学报, 2013(10): 1682-1687.

[7] Lópezcima M F, Garcíapérez J, Pérezgómez B, et al. Lung Cancer Risk and Pollution in an Industrial Region of Northern Spain: a Hospital-based Case-control Study[J]. International Journal of Health Geographics, 2011, 10(2): 186-196.

[8] Wallace J, D'Silva L, Brannan J, et al. Association Between Proximity to Major Roads and Sputum Cell Counts[J]. Canadian Respiratory Journal Journal of the Canadian Thoracic Society, 2010, 18(1): 13-18.

[9] California Environmental Protection Agency, California Air Resources Board. Air Quality and Land Use Handbook: A Community Health Perspective[S]. 2005.

[10] 杨阳. 济南市住区建成环境与家庭出行能耗关系的量化研究 [D]. 清华 大学, 2013 .

[11] Sallis J F, Glanz K. Physical Activity and Food Environments: Solutions to the Obesity Epidemic[J]. Milbank Quarterly, 2009, 87(1): 123-54.

[12] Cervero R, Kockelman K. Travel Demand and the 3Ds: Density, Diversity, and Design[J]. Transportation Research Part D Transport \& Environment, 1997, 2(3): 199-219.

[13] Jing F, Glass T A, Curriero F C, et al. The Built Environment and Obesity: A Systematic Review of the Epidemiologic Evidence[J]. Health \& Place, 2010, 16(2): 175-90

[14] 鲁斐栋, 谭少华. 建成环境对体力活动的影响研究: 进展与思考 [J]. 国际城市规划, 2015, 30(2): 62-70. 
[15] Coutts C. Greenway Accessibility and Physical-activity Behavior[J]. Environment \& Planning B Planning \& Design, 2008, 35(3): 552-563.

[16] 刘志伟. 基于可达性的土地利用与交通需求模型 [D]. 东南大学, 2014.

[17] 冯红霞, 张生瑞. 基于元分维理论的土地利用混合度研究—以榆 林空港生态城控规为例 [J]. 西安建筑科技大学学报: 自然科学版, 2014(6): 882-887.

[18] 周文竹, 阳建强, 葛天阳, 等. 城市用地 “市用地发展模式研究—— 种基于减少机动化需求的规划理念 [J]. 城市规划, 2012, 36(10): 51-57.

[19] Lynott J, Haase J, Nelson K, et al. Planning Complete Streets for an Aging America[J]. Cyclists, 2009.

[20] 张堂. 城市体质健康型人居环境建设研究 [D]. 东华大学, 2011.

[21] 丁沃沃, 胡友培, 荬平平. 城市形态与城市微气候的关联性研究 [J]. 建 筑学报, 2012(7): 16-21.

[22] Kubota T, Miura M, Tominaga Y, et al. Wind Tunnel Tests on the Relationship Between Building Density and Pedestrian-level Wind Velocity: Development of Guidelines for Realizing Acceptable Wind Environment in Residential Neighborhoods[J]. Building \& Environment, 2008, 43(10): 1699-1708.

[23] 余妙, 周俭。小尺度街坊价值、特征及营造理念—都江塭“壹街 区” [C] // 2012 中国城市规划年会. 2012.

[24] 王纪武, 王炜。城市街道峡谷空间形态及其污染物扩散研究——以杭 州市中山路为例 [J]. 城市规划, 2010(12): 57-63.

[25] 邱巧玲, 王凌. 基于街道峡谷污染机理的城市街道几何结构规划研究 [J]. 城市发展研究, 2007, 14(4): 78-82.

[26] 原瑞瑞, 刘海风, 空气质量与城市体育铅炼者健康效应的关联分析 [J]. 四川体育科学, 2014(5): 16-19.

[27] Rojas-Rueda D, Nazelle A D, Teixidó O, et al. Replacing Car Trips by Increasing Bike and Public Transport in the Greater Barcelona Metropolitan Area: A Health Impact Assessment Study[J]. Environment International, 2012, 49: 100-109.

[28] 候芳, 赵文慧, 李志忠, 等. 北京市城区不同等级道路网对可吸入颗粒 物的浓度影响研究 [J]. 测绘科学, 2012, 37(5): 135-137.

[29] 陈刚才, 潘纯珍, 杨清玲, 等. 重庆市主城区交通干道空气污染特征分 析 [J]. 地球与环境, 2004, 32(3): 59-62.

[30] Hitchins J, Morawska L, Wolff R, et al. Concentrations of Submicrometre Particles from Vehicle Emissions Near a Major Road[J]. Atmospheric Environment, 2000, 34(1): 51-59.

[31] Finkelstein M M, Jerrett M, Sears M R. Environmental Inequality and Circulatory Disease Mortality Gradients[J]. Journal of Epidemiology \& Community Health, 2005, 59(6): 481-7.

[32] Zhu Y, Hinds W C, Kim S, et al. Study of Ultrafine Particles near a Major Highway with Heavy-duty Diesel Traffic[J]. Atmospheric Environment, 2002, 36(27): 4323-4335.

[33] Roorda-Knape M C, Janssen N A H, Hartog J D, et al. Traffic Related Air Pollution in City Districts near Motorways[J]. Science of the Total Environment, 1999, 235(1-3): 339-341

[34] Deborah B, John B. A Review of the Urban Development and Transport Impacts on Public Health with Particular Reference to Australia: TransDisciplinary Research Teams and Some Research Gaps[J]. International Journal of Environmental Research \& Public Health, 2009, 6(5): 1557-96.

[35] Rank J, Folke J, Jespersen P H. Differences in Cyclists and Car Drivers Exposure to Air Pollution from Traffic in the City of Copenhagen[J]. Science of the Total Environment, 2001, 279(1-3): 131-6.

[36] 朱长青, 郝生风, 车丽栘, 等。从健康的角度呼呼步行和自行车交通发 展 [J]. 华东公路, 2014(5): 91-93.

[37] Pucher J, Buehler R, Bassett D R, et al. Walking and Cycling to Health: a Comparative Analysis of City, State, and International Data[J]. American Journal of Public Health, 2010, 100(10): 1986-1992.

[38] Rundle A, Diez Roux A V, Free L M, et al. The Urban Built Environment and Obesity in New York City: A Multilevel Analysis[J]. American Journal of Health Promotion Ajhp, 2007, 21 (4 Suppl): 326-334.
[39] Karanasiou A, Viana M, Querol X, et al. Assessment of Personal Exposure to Particulate Air Pollution During Commuting in European CitiesRecommendations and Policy Implications[J]. Science of the Total Environment, 2014, 490(23): 785-797.

[40] City of New York, Active Design Guidelines: Promoting Physical Activity and Health in Design[S]. 2010.

[41] Barton H, Tsourou C, Mitcham C, et al. Healthy Urban Planning in Practice: Experience of European Cities[J]. Healthy Urban Planning in Practice Experience of European Cities, 2003.

[42] Heller J C, Bhatia R. The East Bay Greenway Health Impact Assessment[J]. Prepared for Urban Ecology, 2007.

[43] City of Los Angeles, Gensler. Desighing A Healthy LA[R]. 2013.

[44] 肖玉, 王硕, 李娜, 等. 北京城市绿地对大气 PM2.5 的削减作用 [J]. 资 源科学, 2015, 37(6): 1149-1155.

[45] 吴志萍, 王成, 候晓静, 等. 6 种城市绿地空气 PM2.5 浓度变化规律 的研究 [J]. 安徽农业大学学报, 2008, 35(4): 494-498.

[46] 李萍, 王松, 王亚英, 等.城市道路绿化带 “微峡谷效应” 及其对非机 动车道污染物浓度的影响 [J]. 生态学报, 2011, 31(10): 2888-2896.

[47] 王国玉, 白伟岗, 李新宇, 等。北京地区消减 PM2.5 等颗粒物污染的绿 地设计技术探析 [J]. 中国园林, 2014(7): 70-76.

[48] 冯娴慧, 高克昌, 钟水新. 基于 GRAPES 数值模拟的城市绿地空间布 局对局地微气候影响研究—以广州为例 [J]. 南方建筑, 2014(3): 10-16.

[49] 刘姝宇, 徐雷. 德国居住区规划针对城市气候问题的应对策略 [J]. 建 筑学报, 2010(8): 20-23.

[50] 蔡彦庭, 文雅, 程昫, 等.广州中心城区公园绿地空间格局及可达性分 析 [J]. 生态环境学报, 2011, 20(11): 1647-1652.

[51] Cohen D A, Sehgal A, Williamson S, et al. Park Use and Physical Activity in a Sample of Public Parks in the City of Los Angeles[J]. Rand, 2006.

[52] 李新宇, 赵松婷, 李延明. 北京北小河公园绿地 PM2.5 浓度变化规律 [J]. 园林，2013(6): 20-23.

[53] 胡译文, 秦永胜, 李㭉桓, 等。北京市三种典型城市绿地类型的保健功 能分析 [J]. 生态环境学报, 2011, 20(12): 1872-1878.

[54] 吴志萍, 王成. 城市绿地与人体健康 [J]. 世界林业研究, 2007(2): 32-37.

(本文编辑：秦潇雨） 